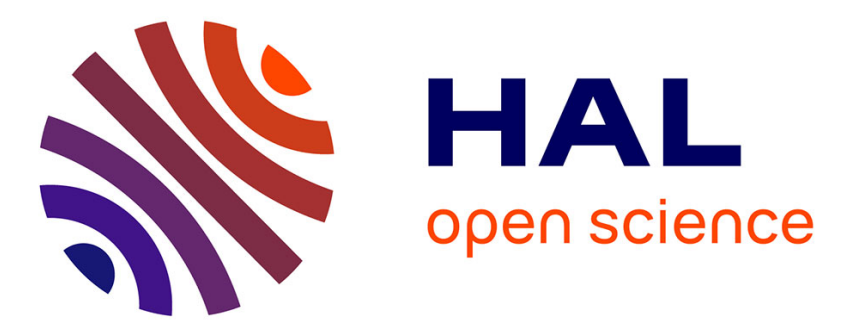

\title{
Restraining deactivation of hierarchical zeolite supported NiW catalysts in the HDS of thiophene
}

Y. Wang, C. Lancelot, C. Lamonier, M. Yang, Y. Sun, J. Morin, Arnaud Rives

\section{To cite this version:}

Y. Wang, C. Lancelot, C. Lamonier, M. Yang, Y. Sun, et al.. Restraining deactivation of hierarchical zeolite supported NiW catalysts in the HDS of thiophene. RSC Advances, 2015, 5 (90), pp.7415074158. 10.1039/c5ra12029b. hal-01869547

\section{HAL Id: hal-01869547 https://hal.science/hal-01869547}

Submitted on 6 Sep 2018

HAL is a multi-disciplinary open access archive for the deposit and dissemination of scientific research documents, whether they are published or not. The documents may come from teaching and research institutions in France or abroad, or from public or private research centers.
L'archive ouverte pluridisciplinaire HAL, est destinée au dépôt et à la diffusion de documents scientifiques de niveau recherche, publiés ou non, émanant des établissements d'enseignement et de recherche français ou étrangers, des laboratoires publics ou privés. 


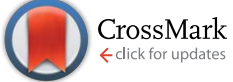

Cite this: RSC Adv., 2015, 5, 74150

Received 22nd June 2015 Accepted 27th August 2015

DOI: $10.1039 / c 5 r a 12029 b$

www.rsc.org/advances

\title{
Restraining deactivation of hierarchical zeolite supported NiW catalysts in the HDS of thiophene $\uparrow$
}

\begin{abstract}
Y. Wang, ${ }^{\text {ab }}$ C. Lancelot, ${ }^{b}$ C. Lamonier, ${ }^{b}$ M. Yang, ${ }^{a}$ Y. Sun, ${ }^{\star a}$ J. C. Morin ${ }^{b}$ and A. Rives ${ }^{\star b}$
$\mathrm{NiW}$ catalysts supported on $\gamma-\mathrm{Al}_{2} \mathrm{O}_{3}\left(\mathrm{NiW} / \mathrm{Al}_{2} \mathrm{O}_{3}\right)$, commercial Beta (NiW/HB) and hierarchical Beta prepared by base-acid treatment (NiW/HB-M) were characterized by X-ray diffraction (XRD), $\mathrm{N}_{2}$ sorption, infrared spectroscopy (IR), transmission electron microscopy (TEM) and X-ray photoelectron spectroscopy (XPS). The catalytic performance of these catalysts was evaluated in the hydrodesulfurization (HDS) of thiophene. The results indicate that NiW/HB as well as NiW/HB-M endured important and rapid deactivation showing that the introduction of additional mesopores/macropores in the support could not prevent the deactivation tendency. Interestingly, NiW/HB or NiW/HB-M mixed with $\mathrm{NiW} / \mathrm{Al}_{2} \mathrm{O}_{3}$ and the utilization of $\mathrm{Na}^{+}$-exchanged Beta as a support remarkably improved the anti-deactivation ability of the catalysts. As a result, the catalysts NiW/NaB-M (NiW catalyst supported on $\mathrm{Na}^{+}$-exchanged hierarchical Beta) and NiW/2OHB-M (20\% NiW/HB-M mixed with $\left.80 \% \mathrm{NiW} / \mathrm{Al}_{2} \mathrm{O}_{3}\right)$ gave superior catalytic activity than $\mathrm{NiW} / \mathrm{Al}_{2} \mathrm{O}_{3}$.
\end{abstract}

\section{Introduction}

Transition metal $\mathrm{Ni}(\mathrm{Co}) \mathrm{Mo}(\mathrm{W})$ sulfide (TMS) catalysts are important industrial catalysts for the hydrodesulfurization (HDS) of transportation fuels in oil refinery. Generally, TMS catalysts need to be supported on a carrier like alumina and the support plays a vital role in determining the catalytic activity and stability. ${ }^{1-3}$ It is generally accepted that a support with strong Brönsted acid sites is beneficial for promoting the HDS performance of catalysts ${ }^{4-9}$ because it could enhance the adsorption properties of sulfur-containing molecules ${ }^{8}$ and optimize the electronic properties of active phases. ${ }^{9}$ Thus, zeolites with such acid sites have been widely investigated as support of HDS catalysts. ${ }^{10}$ However, some studies indicated that zeolites supported TMS catalysts exhibited lower catalytic activity than alumina supported TMS catalysts in some HDS reactions. ${ }^{11-16}$ One explanation is that active phases located in micropores of zeolites might be difficult to access for the reactants. Additionally, it has been reported that microporous zeolite based TMS catalysts underwent a significant deactivation, which could be stabilized during the first few hours. ${ }^{15,16}$ Such an initial deactivation would remarkably decrease the activity of zeolite supported catalysts.

To overcome the drawbacks associated to microporous zeolites, the utilization of hierarchical zeolites as support of

${ }^{a}$ School of Chemical Engineering and Technology, Harbin Institute of Technology, Harbin, 150001, China. E-mail: yysun@hit.edu.cn

${ }^{b}$ Unité de Catalyse et Chimie du Solide, UCCS, UMR CNRS 8181, Université Lille Nord de France, 59655 Villeneuve d'Ascq, France. E-mail: alain.rives@univ-lille1.fr

$\dagger$ Electronic supplementary information (ESI) available. See DOI: $10.1039 / \mathrm{c} 5 \mathrm{ra} 12029 \mathrm{~b}$
TMS catalyst has been considered as the active phases located in mesopores/macropores could be more easily accessible to the reactants and the diffusion ability can also be improved due to the introduction of these additional pores. Indeed, there are some reports about this subject. For examples, Ni(Co)Mo catalyst was supported on hierarchical zeolite L, ${ }^{13,17}$ ZSM-5 (ref. 18), and mordenite ${ }^{19}$ for HDS reactions. The results indicated that hierarchical zeolites supported Ni(Co)Mo catalyst exhibited superior catalytic performance than microporous zeolites supported one. This demonstrated that the introduction of additional mesopores/macropores in zeolite supports is helpful for enhancing the HDS catalytic performance in agreement with better accessibility of active phases.

On the other hand, it is well known that conventional zeolites deactivated easily in some acid-catalytic reactions and the introduction of hierarchical pores into zeolites can improve the resistance ability to deactivation..$^{20-22}$ One explanation is that external active sites outside micropores were able to perform the catalytic function even after active sites inside micropores were deactivated. ${ }^{21}$ Thus, from the viewpoint of deactivation the use of hierarchical zeolites as the support of TMS catalysts might inhibit deactivation of catalysts to some extent. Nevertheless, the study about deactivation situation of hierarchical zeolites supported TMS catalysts in the HDS reactions has not been presented.

In this present work, we prepared hierarchical Beta supported NiW catalyst as a representative of hierarchical zeolites supported TMS catalysts. The deactivation of zeolite based catalysts was investigated in HDS of thiophene. The effects of mechanical mixture of the catalysts with $\mathrm{NiW} / \mathrm{Al}_{2} \mathrm{O}_{3}$ and the use of $\mathrm{Na}^{+}$exchanged Beta zeolite as support were also considered to restrain the deactivation. 


\section{Experimental}

\subsection{Materials}

Commercial Beta was purchased to the Catalyst Plant of Nankai University. $\mathrm{HNO}_{3}, \mathrm{NaOH}, \mathrm{NH}_{4} \mathrm{NO}_{3}, \mathrm{NaNO}_{3}$ were purchased to Sinopharm Chemical Reagent Co., and thiophene to SigmaAldrich and used without further purification.

\subsection{Preparation of catalysts}

H-form conventional and hierarchical Beta. H-form conventional Beta (HB) was obtained by calcining commercial $\mathrm{NH}_{4}{ }^{+}$form Beta zeolite at $823 \mathrm{~K}$ for $5 \mathrm{~h}$. $\mathrm{H}$-form hierarchical Beta (HB-M) was prepared according to the literature. ${ }^{23}$ The sample HB was treated with a solution of $0.2 \mathrm{M} \mathrm{NaOH}$ with a liquid-tosolid ratio of $30 \mathrm{ml} \mathrm{g}^{-1}$ at $338 \mathrm{~K}$ for $0.5 \mathrm{~h}$. Then, the product was filtered, washed with deionized water, dried, ion-exchanged into $\mathrm{NH}_{4}$-form, and calcined at $823 \mathrm{~K}$ for $5 \mathrm{~h}$. It was then treated with a solution of $0.1 \mathrm{M} \mathrm{HNO}_{3}$ at $338 \mathrm{~K}$ for $6 \mathrm{~h}$ with a liquid-to-solid ratio of $30 \mathrm{ml} \mathrm{g}^{-1}$. The product was ionexchanged as described above, followed by calcination at $823 \mathrm{~K}$ for $3 \mathrm{~h}$ to obtain the sample labelled as HB-M.

HB and HB-M supported NiW catalysts. The supported NiW catalysts were prepared by co-impregnation using the incipient wetness technique. Typically, the impregnation solution was obtained by dissolution of nickel nitrate hexahydrate and ammonium metatungstate in water with a $\mathrm{W} / \mathrm{Ni}$ molar ratio of 2.75 based on our previous study. ${ }^{24-27}$ The calculated content of $\mathrm{WO}_{3}$ in catalyst was $15 \mathrm{wt} \%$. These catalysts were dried at $373 \mathrm{~K}$ overnight and then calcined at $773 \mathrm{~K}$ for $4 \mathrm{~h}$ in air, using a temperature ramp of $2 \mathrm{~K} \mathrm{~min}^{-1}$. The chemical composition of various catalysts was listed in Table 1 . The HB and HB-M supported NiW catalysts were labelled as NiW/HB and NiW/HB-M, respectively. For comparison, commercial alumina (BET surface area: $220 \mathrm{~m}^{2} \mathrm{~g}^{-1}$, external surface area: $218 \mathrm{~m}^{2} \mathrm{~g}^{-1}$, pore volume measured by water adsorption: $0.6 \mathrm{ml} \mathrm{g}^{-1}$ ) supported NiW catalyst prepared by the same method was named as $\mathrm{NiW} / \mathrm{Al}_{2} \mathrm{O}_{3}$.

Mixed catalysts. The mixed catalysts were prepared by mechanically mixing $x$ wt $\%$ NiW/HB or NiW/HB-M $(x=20,50$, 80) with $\mathrm{NiW} / \mathrm{Al}_{2} \mathrm{O}_{3}$ and were accordingly labelled as $\mathrm{NiW} / x \mathrm{HB}$ or $\mathrm{NiW} / x \mathrm{HB}-\mathrm{M}$.

$\mathrm{Na}^{+}$-exchanged conventional and hierarchical Beta. $\mathrm{HB}$ or HB-M was treated with $1 \mathrm{M} \mathrm{NaNO}_{3}$ with a liquid-to-solid ratio of $100 \mathrm{ml} \mathrm{g}^{-1}$ at room temperature for $2 \mathrm{~h}$. This ion-exchanged process was repeated twice. Then, the product was dried overnight, calcined at $823 \mathrm{~K}$ for $5 \mathrm{~h}$ and labelled as NaB or NaB-M.

NaB and NaB-M supported NiW catalysts. $\mathrm{NaB}$ or $\mathrm{NaB}-\mathrm{M}$ supported NiW catalysts were prepared according to the above-mentioned method. The obtained catalysts were labelled as NiW/NaB and NiW/NaB-M, respectively.

\subsection{Catalyst characterization}

Inductively Coupled Plasma-Optical Emission Spectroscopy (ICP-OES) results were determined after acidic digestion of zeolites based catalysts in a mixture of fluorhydric acid $(3 \mathrm{ml})$ and nitric acid $(5 \mathrm{ml})$ under closed vessels microwave (600 watts) for a duration of 40 minutes. Acidic mineralisations were then analyzed using ICP-OES for nickel, aluminium and tungsten. Silicon was analyses by Flame Atomic Absorption Spectroscopy (FAAS) in order to avoid spectral interference that could exist in ICP-OES. X-ray powder diffraction (XRD) patterns were recorded using a Siemens D-5000 diffractometer equipped with the $\mathrm{Cu} \mathrm{K} \alpha$ radiation (wavelength of $\lambda=1.5418 \AA$ ) and using the two cycle diffractometer equipped by six detectors having $\mathrm{Si}(111)$ analyzer crystals and $\mathrm{Na}-\mathrm{I}$ scintillation counters. Nitrogen sorption isotherms were obtained at $77 \mathrm{~K}$ on a Micromeritics TriStar II 3020 Gas Sorption and Porosimetry system. Prior to the experiments, the samples were outgassed at $423 \mathrm{~K}$ under vacuum for $3 \mathrm{~h}$. Temperature-programmed desorption of $\mathrm{NH}_{3}\left(\mathrm{NH}_{3}\right.$-TPD) was carried out on a Micromeritics AutoChem II 2920 system equipped with a thermal conductivity detector. The samples were first outgassed under $823 \mathrm{~K}$ for $1 \mathrm{~h}$ before the measurement. After cooling to $373 \mathrm{~K}$, the samples were saturated in an $\mathrm{NH}_{3}$ stream (5\% in $\mathrm{Ar}$ ) for $1 \mathrm{~h}$ and consequently treated in $\operatorname{Ar}\left(30 \mathrm{ml} \mathrm{min}^{-1}\right)$ for $2 \mathrm{~h}$ for removing physisorbed $\mathrm{NH}_{3}$. Finally, the TPD profile was determined by increasing temperature from $373 \mathrm{~K}$ to $873 \mathrm{~K}$ with a heating rate of $5 \mathrm{~K} \mathrm{~min}^{-1}$ while recording $\mathrm{NH}_{3}$ desorption with a thermal conductivity detector. The IR studies of pyridine and pivalonitrile adsorption were carried out to measure the number of acid sites and accessible acid sites, respectively, recorded with a Nicolet Protege System 460 equipped with a DTGS detector. All samples were ground in an agate mortar and were pressed into the form of self-supporting wafers $\left(5 \mathrm{mg} \mathrm{cm}^{-2}\right.$ ), then heated at $723 \mathrm{~K}$ under high vacuum $\left(10^{-6} \mathrm{mbar}\right)$ for $2 \mathrm{~h}$ and cooled down before probe molecule adsorption. All recorded spectra were recalculated to a normalized wafer of $10 \mathrm{mg}$. The concentration of Brönsted and Lewis acid sites was determined by quantitative IR studies of probe molecule adsorption experiments. In order to quantify Lewis and Brönsted acid sites, FTIR spectrum of the activated surface was substract from the pivalonitrile and pyridine adsorbed one. For experiments based on pyridine adsorption, the following bands and absorption coefficients were used:

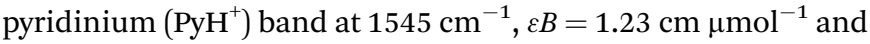

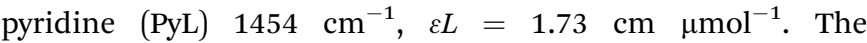

Table 1 Chemical composition of various catalysts from ICP-OES FAAS measurements and the acidity of supports at $423 \mathrm{~K}$

\begin{tabular}{llllll}
\hline Samples & & & Number of Brönsted & $\begin{array}{l}\text { Number of accessible Brönsted } \\
\text { acid sites }\left(\times f \mu \mathrm{mol} \mathrm{g}^{-1}\right)\end{array}$ \\
\hline NiW/HB & $\mathrm{Si} / \mathrm{Al}$ & $\mathrm{WO}_{3}(\mathrm{wt} \%)$ & $\mathrm{Wi}\left(\mu \mathrm{mol} \mathrm{g}^{-1}\right)$ & 269 & 2.0 \\
NiW/HB-M & 17 & 16.6 & 2.4 & 209 & 9.5
\end{tabular}


concentration of accessible Brönsted and Lewis acid sites was determined by quantitative IR studies of pivalonitrile adsorption experiments using the following bands and absorption coefficients were used: pivalonitrile $\left(\mathrm{PiH}^{+}\right)$band at $2274 \mathrm{~cm}^{-1}$,

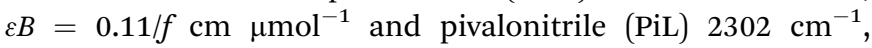
$\varepsilon L=0.15 / f{\mathrm{~cm} \mu \mathrm{mol}^{-1}}$, where $f$ was a constant depending on the IR system. For bands with several contributions spectra were decomposed using Omnic software 8.3. X-ray photoelectron spectroscopy (XPS) was performed on an Axis ultra DLD (Kratos analytical) using a monochromatic Al $\mathrm{K} \alpha \mathrm{X}$-ray source $(h \nu=$ $1486.6 \mathrm{eV})$. The emission voltage and the current of this source were set to $15 \mathrm{kV}$ and $10 \mathrm{~mA}$, respectively. The pressure in the analyzing chamber was maintained at $10^{-9} \mathrm{~Pa}$ or lower during analysis, and the size of the analyzed area was $300 \times 700 \mu \mathrm{m}^{2}$. After their sulfidation under $\mathrm{H}_{2} / \mathrm{H}_{2} \mathrm{~S}(90 / 10)$ for $2 \mathrm{~h}$ at $673 \mathrm{~K}$, samples were transferred into the spectrometer chamber using a gloves box in order to avoid any reoxydation. Surveys (0-1300 eV) were recorded at pass energies of $160 \mathrm{eV}$ with a step of $1 \mathrm{eV}$ and high-resolution (W4f, Ni2p, S2p and C 1s zone) spectra were recorded at pass energies of $40 \mathrm{eV}$ with a step of $0.1 \mathrm{eV}$. Data treatment and peak-fitting procedures were performed using Casa XPS software. Obtained spectra were calibrated in respect of $\mathrm{C} 1 \mathrm{~s}$ (C-C bond) at $285 \mathrm{eV}$. The peaks were decomposed using Gaussian-Lorentzian peak shapes. High resolution transmission electron microscopy (HRTEM) analysis was performed on a TECNAI microscope operating at $200 \mathrm{kV}$ with a $\mathrm{LaB}_{6}$ crystal. Freshly sulfided samples were ground under an inert atmosphere and dispersed in ethanol. The suspension was collected on carbon films supported on copper grids. For statistical analysis, more than 60 photographs were taken for each sample, which enable us to manually measure more than $600 \mathrm{WS}_{2}$ slabs. The statistical analysis was performed by measuring the length and stacking number of the slabs.

\subsection{Catalytic tests}

The HDS of thiophene was performed in a fixed-bed tubular reactor. The reactor was loaded with $0.2 \mathrm{~g}$ of catalyst. Then the catalysts were pre-sulfided at atmospheric pressure at $673 \mathrm{~K}$ for $3 \mathrm{~h}\left(6 \mathrm{~K} \mathrm{~min}^{-1}\right)$ using a mixture of 10 vol\% $\mathrm{H}_{2} \mathrm{~S}$ in $\mathrm{H}_{2}$ at a total flow rate of $100 \mathrm{ml} \mathrm{min}^{-1}$. The reactions were then carried out at $623 \mathrm{~K}$ with $20 \mathrm{ml} \mathrm{min}{ }^{-1} \mathrm{H}_{2}$ and $1.4 \mathrm{ml} \mathrm{min}^{-1}$ thiophene. The reaction samples were withdrawn at regular intervals and analyzed by gas chromatography on an Agilent 6890 GC with an FID detector.

\section{Results}

\subsection{Characterizations}

The powder XRD patterns of all the samples are presented in Fig. 1. HB and HB-M exhibited well resolved diffraction peaks, which are characteristic for Beta zeolite framework structure. After supporting NiW catalyst, the zeolite structure was still maintained and no detectable diffraction peaks assigned to $\mathrm{WO}_{3}$ and $\mathrm{NiO}$ were observed. This suggested that tungsten and nickel oxidic species were either completely amorphous or

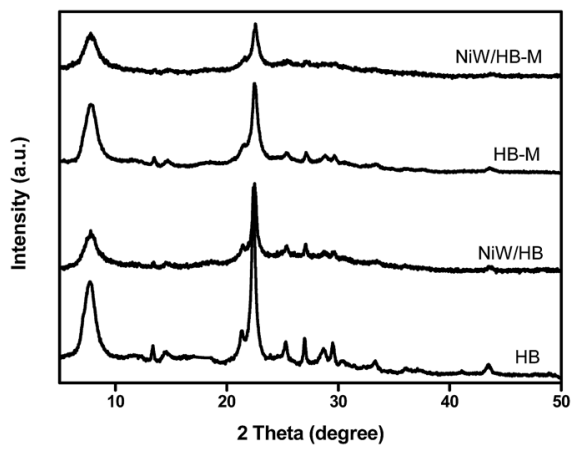

Fig. 1 X-ray diffraction patterns of various samples.

composed of crystallites smaller than $4 \mathrm{~nm},{ }^{28-30}$ indicating a good dispersion of the metals.

The $\mathrm{N}_{2}$ sorption isotherms of HB, HB-M and their corresponding catalysts are shown in Fig. 2. They exhibited a type I isotherm at low relative pressure and a type IV isotherm with a hysteresis loop at high relative pressure, indicating the existence of hierarchical pores. The detailed sorption data are listed in Table 2. For the catalysts, surface areas and pore volumes were also expressed per gram of support, by deducing the weight gain due to the active phase, in order to estimate the variations of the textural properties of the support itself. It can be observed that the micropore volume, external surface area and mesopore volume of $\mathrm{HB}$ and HB-M decreased after impregnation, suggesting that NiW active phase could be dispersed in both micropores and mesopores. The pore distribution of the samples (Fig. 2) appeared not affected after impregnation step.

The acidity of support was measured by $\mathrm{NH}_{3}$-TPD and IR study of pyridine/pivalonitrile adsorption to reflect the acidity of catalysts. It can be seen from $\mathrm{NH}_{3}$-TPD results that both $\mathrm{HB}$ and HB-M exhibited two desorption peaks at about $260{ }^{\circ} \mathrm{C}$ and $450{ }^{\circ} \mathrm{C}$ (Fig. 3), suggesting that they had similar acid strength. The quantity of acid sites is higher in the case of HB support indicating that the treatment of the support led to a decrease of global acidity.
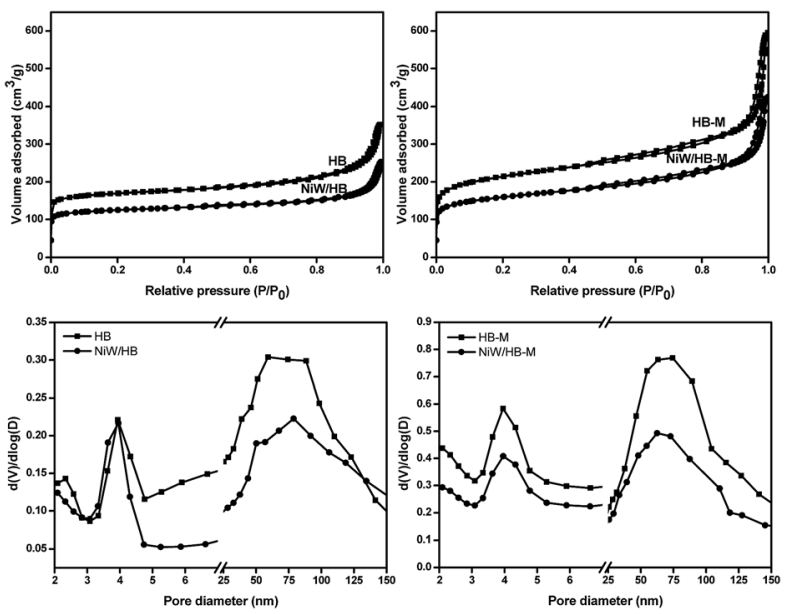

Fig. $2 \mathrm{~N}_{2}$ sorption isotherms and pore distribution of various samples. 
Table $2 \quad \mathrm{~N}_{2}$ sorption data of various catalysts

\begin{tabular}{lllll}
\hline Samples & $\begin{array}{l}\text { BET surface area } \\
\left(\mathrm{m}^{2} \mathrm{~g}^{-1}\right)\end{array}$ & $\begin{array}{l}\text { External surface area } \\
\left(\mathrm{m}^{2} \mathrm{~g}^{-1}\right)\end{array}$ & $\begin{array}{l}\text { Micropore volume }^{a} \\
\left(\mathrm{~cm}^{3} \mathrm{~g}^{-1}\right)\end{array}$ & $\begin{array}{l}\text { Mesopore volume }^{b} \\
\left(\mathrm{~cm}^{3} \mathrm{~g}^{-1}\right)\end{array}$ \\
\hline $\mathrm{HB}$ & 550 & 134 & 0.20 & 0.34 \\
$\mathrm{NiW} / \mathrm{HB}$ & $407\left(507^{c}\right)$ & $98\left(121^{c}\right)$ & 0.18 & $\left.0.18^{c}\right)$ \\
$\mathrm{HB}-\mathrm{M}$ & 717 & 348 & $0.14\left(0.16^{c}\right)$ & $0.74\left(0.30^{c}\right)$ \\
NiW/HB-M & $531\left(623^{c}\right)$ & $242\left(284^{c}\right)$ & & $0.52\left(0.61^{c}\right)$ \\
${ }^{a}{ }^{c}$-plot method. ${ }^{b}{ }^{c}$ BJH method. $^{c}$ Data calculated by deducting the effect of NiW mass. & &
\end{tabular}

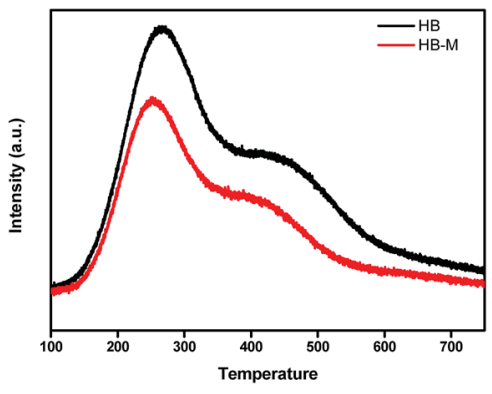

Fig. $3 \mathrm{NH}_{3}-\mathrm{TPD}$ profiles for $\mathrm{HB}$ and $\mathrm{HB}-\mathrm{M}$.

By IR studies of pyridine adsorption (Table 1) it is also shown that HB-M possessed less number of Brönsted acid sites $\left(209 \mu \mathrm{mol} \mathrm{g}^{-1}\right)$ than HB $\left(269 \mu \mathrm{mol} \mathrm{g}^{-1}\right)$ as observed on the global acidity.

In order to try to discriminate between Brönsted acid sites present in micropores and mesopores, a larger basic molecule, pivalonitrile, was used to probe the accessible acid sites. The number of these external Brönsted acid sites is five times larger in HB-M than that in HB in agreement with the larger pore volume of the treated zeolite.

Fig. 4 showed the XPS spectra of W4f for the sulfided catalysts. The methodology implemented for the decomposition of the spectra of the W4f has been described elsewhere. ${ }^{24-27}$ The decomposition of the photopeaks revealed three contributions attributed to $\mathrm{W}^{6+}$ in an oxidic environment (W4f5/2: $36.2 \mathrm{eV}$ and $\mathrm{W} 4 \mathrm{f} 3 / 2: 38.3 \mathrm{eV}$ ), $\mathrm{W}^{5+}$ as oxysulfide species ( $33.2 \mathrm{eV}$ and $35.4 \mathrm{eV}$ ) and $\mathrm{W}^{4+}$ sulfided species $(32.3 \mathrm{eV}$ and $34.4 \mathrm{eV}){ }^{25,27,31,32}$ The data obtained from these decompositions are listed in Table 3. The $\mathrm{WS}_{2}$ is representative of the sulfidation degree of tungsten. For $\mathrm{NiW} / \mathrm{Al}_{2} \mathrm{O}_{3}$, it was about $30 \%$, which was in agreement with previous works. ${ }^{27,33}$ In comparison, higher sulfidation degree was obtained for NiW/HB (73\%) and NiW/HB-M (58\%), which is in accordance with other reported works about that the use of zeolite support improving the sulfidation degree of $\mathrm{Ni}(\mathrm{Co})$ $\mathrm{Mo}(\mathrm{W})$ catalyst..$^{28,34}$ This result might be related to the relatively weak interaction between active phase and zeolitic support because Si species had weaker interaction than $\mathrm{Al}$ species with $\mathrm{Mo}(\mathrm{W})$ active phase. ${ }^{35}$

The XPS spectra for Ni2p are presented in Fig. 5 . The fitting parameter for XPS decomposition in the energy emission region of Ni2p has been reported elsewhere. ${ }^{31}$ Their decomposition evidenced three contributions: Nickel sulfides $\mathrm{Ni}_{x} \mathrm{~S}_{y}(\mathrm{Ni} 2 \mathrm{p} 3 / 2$ :

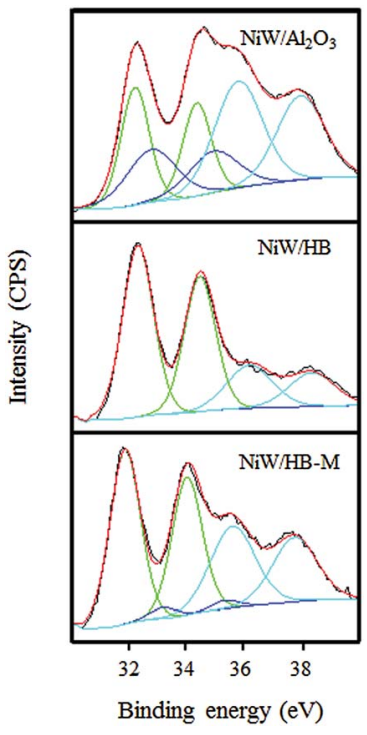

Fig. 4 Emission region of W4f XPS spectra of various catalysts sulfided at $673 \mathrm{~K}$ with their fit decomposition curves: experimental (black), simulation (red), $\mathrm{WS}_{2}$ (green), $\mathrm{WO}_{x} \mathrm{~S}_{y}$ (blue), $\mathrm{W}^{6+}$ (cyan).

852.6 eV, Ni2p1/2: $869.8 \mathrm{eV})$, NiWS (Ni2p3/2: $853.7 \mathrm{eV}$, $\mathrm{Ni2p} 1 / 2: 870.9 \mathrm{eV})$ and an oxidic phase $\mathrm{Ni}^{2+}(\mathrm{Ni} 2 \mathrm{p} 3 / 2: 856.4 \mathrm{eV}$, Ni2p1/2: $873.8 \mathrm{eV}) .{ }^{25,27,31,32}$ The proportions of NiO, $\mathrm{Ni}_{x} \mathrm{~S}_{y}$ and NiWS in the catalysts were calculated and listed in Table 4 . The proportion of NiWS species is representative of the promotion degree of $\mathrm{WS}_{2}$ slabs by the nickel. A proportion of $44 \%$ NiWS was obtained in $\mathrm{NiW} / \mathrm{Al}_{2} \mathrm{O}_{3}$, which was similar to that in the previous work. ${ }^{32}$ Comparatively, the promotion degree of Ni was $52 \%$ and $33 \%$ in NiW/HB and NiW/HB-M, respectively.

Representative TEM images of the sulfided catalysts are shown in Fig. 6. All the samples exhibited the typical structure of the layered $\mathrm{WS}_{2}$ phase, with an interplanar spacing of $0.65 \mathrm{~nm}$, corresponding to the (002) planes of the $\mathrm{WS}_{2}$ crystal. $^{36}$ No agglomeration could be observed. By the statistical analysis

Table 3 Percentage of various W species in catalysts after sulfidation

\begin{tabular}{llll}
\hline Samples & $\mathrm{WS}_{2}(\%)$ & $\mathrm{WO}_{x} \mathrm{~S}_{y}(\%)$ & $\mathrm{W}^{6+}(\%)$ \\
\hline $\mathrm{NiW} / \mathrm{Al}_{2} \mathrm{O}_{3}$ & 30 & 24 & 46 \\
$\mathrm{NiW} / \mathrm{HB}$ & 73 & 0 & 27 \\
$\mathrm{NiW} / \mathrm{HB}-\mathrm{M}$ & 58 & 3 & 39
\end{tabular}




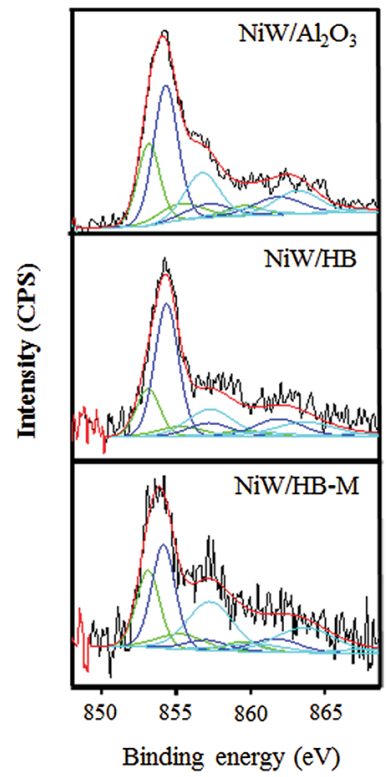

Fig. 5 Emission region of Ni2p XPS spectra of various catalysts sulfided at $673 \mathrm{~K}$ with their fit decomposition curves: experimental (black), simulation (red), $\mathrm{Ni}_{x} \mathrm{~S}_{y}$ (green), NiWS (blue), $\mathrm{Ni}^{2+}$ (cyan).

Table 4 Percentage of various Ni species in catalysts after sulfidation

\begin{tabular}{llll}
\hline Samples & NiWS $(\%)$ & $\mathrm{Ni}_{x} \mathrm{~S}_{y}(\%)$ & $\mathrm{Ni}^{2+}(\%)$ \\
\hline $\mathrm{NiW} / \mathrm{Al}_{2} \mathrm{O}_{3}$ & 44 & 27 & 29 \\
$\mathrm{NiW} / \mathrm{HB}$ & 52 & 20 & 28 \\
$\mathrm{NiW} / \mathrm{HB}-\mathrm{M}$ & 33 & 26 & 41
\end{tabular}

of the images, the distributions in slab length and stacking of the $\mathrm{WS}_{2}$ slabs were obtained (Fig. 7). On sulfided $\mathrm{NiW} / \mathrm{Al}_{2} \mathrm{O}_{3}$, the $\mathrm{WS}_{2}$ slab length was between 1 and $10 \mathrm{~nm}$ with an average length $(L)$ of $4.8 \mathrm{~nm}$ and an average stacking number $(N)$ of 1.2. The length of $\mathrm{WS}_{2}$ slabs in NiW/HB was distributed between 1 to $13 \mathrm{~nm}$. The calculated average $L$ and $N$ were $4.8 \mathrm{~nm}$ and 3.3, respectively. Additionally, the length of $\mathrm{WS}_{2}$ slabs in NiW/HB-M was distributed in a narrower range of 1-7 nm with average values of $2.6 \mathrm{~nm}(L)$ and $2.6(N)$. It has been reported in earlier literatures that the active phase over zeolite support would be larger and more stacked than that over alumina support, ${ }^{14,28,34}$ which was in agreement with our results. This can be explained by a weaker interaction developed on the zeolite support by the sulfided phase compared to alumina, well known for its dispersion ability. ${ }^{14}$
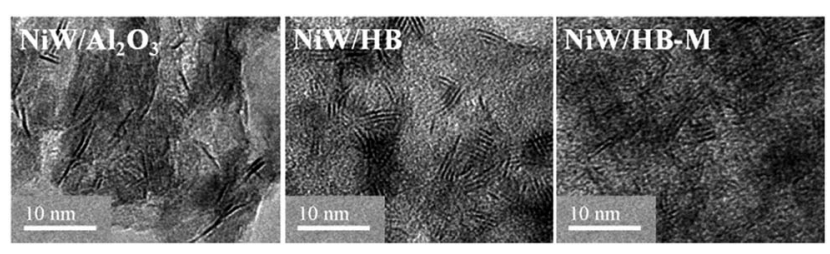

Fig. 6 HRTEM images of sulfided $\mathrm{NiW} / \mathrm{Al}_{2} \mathrm{O}_{3}, \mathrm{NiW} / \mathrm{HB}$ and NiW/HB-M.
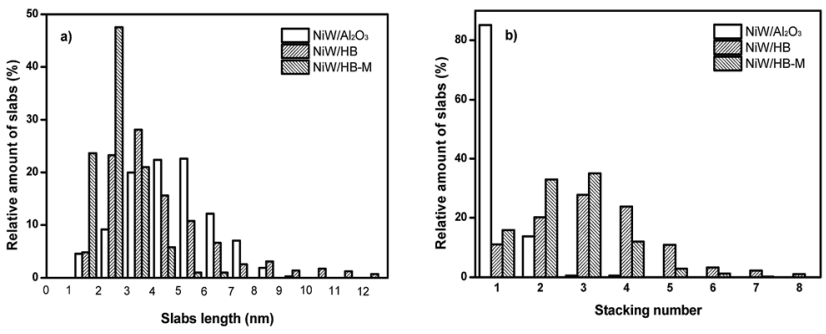

Fig. 7 Distribution of the length (a) and stacking number (b) of the $\mathrm{WS}_{2}$ slabs over various supports.

\subsection{Catalytic evaluation}

The catalytic performance of these catalysts was evaluated in the HDS of thiophene. The main HDS reaction pathway in this reaction was shown in Scheme 1. Only four products (1-butene, cis- and trans-2-butene, $n$-butane) can be detected over $\mathrm{NiW} / \mathrm{Al}_{2} \mathrm{O}_{3}$. In comparison, some additional products (such as ethane, ethylene, propane and propene) were detected over NiW/ HB and NiW/HB-M due to the strong acidity of the support. No dihydrothiophene, tetrahydrothiophene and 1,3-butadiene were detected because they can be quickly converted into butane and butenes. Moreover, a small amount of unidentified large molecules were detected over NiW/HB and NiW/HB-M, which might be attributed to the polymerization of olefins.

The reaction rate of thiophene over various catalysts with time on stream was shown in Fig. 8. The activities after 15 minutes and 3 hours of reaction over these catalysts are listed in Table 5 . Here, we can consider the activity at a reaction time of $3 \mathrm{~h}$ as the steady-state because activity tended to be stable after this time. Obviously, no deactivation was observed over $\mathrm{NiW} / \mathrm{Al}_{2} \mathrm{O}_{3}$ within a reaction time of $8 \mathrm{~h}$ with an activity around $177 \mathrm{~L} \mathrm{~h}^{-1} \mathrm{~mol}^{-1} \mathrm{~W}$. In comparison, NiW/HB displayed higher initial activity $\left(385 \mathrm{~L} \mathrm{~h}^{-1} \mathrm{~mol}^{-1} \mathrm{~W}\right)$ than $\mathrm{NiW} / \mathrm{Al}_{2} \mathrm{O}_{3}$. However, rapid deactivation occurred and the catalytic activity was stabilized after a reaction time of $3 \mathrm{~h}$. The steady-state activity of $\mathrm{NiW} / \mathrm{HB}$ was $71 \mathrm{~L} \mathrm{~h}^{-1} \mathrm{~mol}^{-1} \mathrm{~W}$, which was much lower than that of $\mathrm{NiW} / \mathrm{Al}_{2} \mathrm{O}_{3}$. Further, NiW/HB-M exhibited highest initial activity $\left(473 \mathrm{~L} \mathrm{~h}^{-1} \mathrm{~mol}^{-1} \mathrm{~W}\right)$ among these catalysts. Nevertheless, rapid deactivation was also observed over NiW/HB-M. After a reaction time of $3 \mathrm{~h}$, the activity reached $195 \mathrm{~L} \mathrm{~h}^{-1} \mathrm{~mol}^{-1} \mathrm{~W}$.

The steady-state selectivity of products over various catalysts was shown in Fig. 9. Only $n$-butane, 1- and 2-butenes (C4

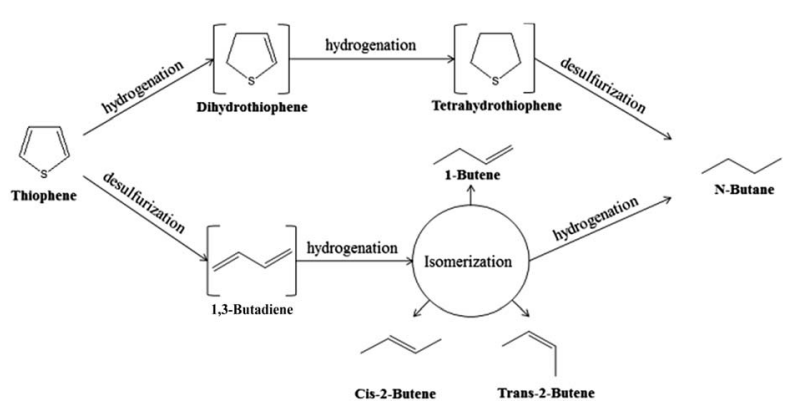

Scheme 1 Main reaction pathway for thiophene hydrodesulfurization. 


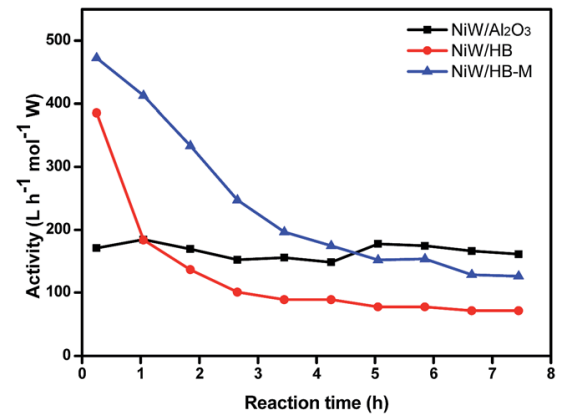

Fig. 8 Catalytic activity of various catalysts with time-on-stream in HDS of thiophene.

products) were observed over $\mathrm{NiW} / \mathrm{Al}_{2} \mathrm{O}_{3}$. For $\mathrm{NiW} / \mathrm{HB}$, some cracking products (C2 $2 \%, \mathrm{C} 312 \%$ ) as well as polymerized products (others 14\%) could be detected besides major C4 products (72\%). Comparatively, NiW/HB-M exhibited higher cracking activity (C2 3\%, C3 19\%) than NiW/HB, which might be related to the larger number of accessible acid sites in HB-M as the number of acid sites located in mesopores/macropores could be less reduced than that in micropores during deactivation. ${ }^{21,37}$

\section{Discussions}

\subsection{Location of NiW active phase}

In general, the promotion degree in TMS catalysts should have a good relationship with the sulfidation degree because the existence of more species like $\mathrm{W}(\mathrm{Mo}) \mathrm{S}_{2}$ can result in higher possibility of formation for the species like NiW(Mo)S. In this work, although NiW/HB-M exhibited higher sulfidation degree $(58 \%)$ than $\mathrm{NiW} / \mathrm{Al}_{2} \mathrm{O}_{3}(30 \%)$, the promotion degree in $\mathrm{NiW} /$ HB-M (33\%) was lower than that in NiW/ $/ \mathrm{Al}_{2} \mathrm{O}_{3}$ (44\%). Similarly, the sulfidation degree in NiW/HB (73\%) was twice more than that in $\mathrm{NiW} / \mathrm{Al}_{2} \mathrm{O}_{3}(30 \%)$ while the promotion degree $(52 \%)$ in NiW/HB was only slightly higher than that (44\%) in NiW/ $\mathrm{Al}_{2} \mathrm{O}_{3}$. This means that $\mathrm{Ni}$ species might not efficiently promote the sulfided $\mathrm{W}$ species in HB and HB-M.

To explain the above results, an imaginative diagram about the distribution of active phase in micropores and mesopores/ macropores of zeolite Beta was proposed (Scheme 2). As shown, Ni species might be located in both micropores and mesopores/macropores of zeolite Beta, whereas W species could be only located in mesopores/macropores. Such supposition was mainly based on the consideration of preparation process for the introduction of the active phase. In this work, the

Table 5 Initial and steady-state activity of various catalysts

\begin{tabular}{llll}
\hline Catalysts & $\mathrm{NiW} \mathrm{Al}_{2} \mathrm{O}_{3}$ & $\mathrm{NiW} / \mathrm{HB}$ & $\mathrm{NiW} / \mathrm{HB}-\mathrm{M}$ \\
\hline $\begin{array}{l}\text { Initial activity } \\
\left(\mathrm{L} \mathrm{h} \mathrm{mol}^{-1} \mathrm{~W}\right)\end{array}$ & 177 & 385 & 473 \\
$\begin{array}{l}\text { Steady-state activity } \\
\left(\mathrm{L} \mathrm{h}^{-1} \mathrm{~mol}^{-1} \mathrm{~W}\right)\end{array}$ & 177 & 71 & 195
\end{tabular}

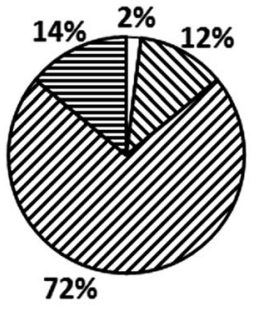

NiW/HB
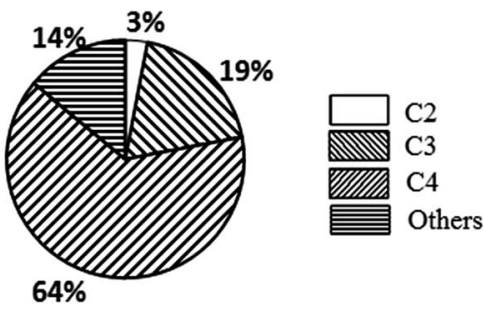

Fig. 9 Product selectivity of NiW/HB and NiW/HB-M at steady-state in HDS of thiophene. precursors of active phase were nickel nitrate hexahydrate and ammonium metatungstate. During the impregnation, $\mathrm{Ni}^{2+}$ from the precursor of Ni species can enter the pores of zeolite Beta, including micropores, due to its small cation size. However, it will be more difficult for $\mathrm{H}_{2} \mathrm{~W}_{12} \mathrm{O}_{40}{ }^{6-}$ from the precursor of $\mathrm{W}$ species to enter the micropores because the size of the anion is relatively large. $\mathrm{Ni}$ species might thus be located in both micropores and mesopores/macropores of zeolite Beta and $\mathrm{W}$ species only in mesopores/macropores. This means that only $\mathrm{Ni}$ species located in mesopores can play a promotion role on $\mathrm{WS}_{2}$. This hypothesis can explain why NiW/HM and NiW/HM-M with high sulfidation degree did not accordingly display high promotion degree.

\subsection{Deactivation of hierarchical Beta supported catalyst}

As shown in Fig. 8, NiW/HB-M and NiW/HB exhibited largely higher initial activity than $\mathrm{NiW} / \mathrm{Al}_{2} \mathrm{O}_{3}$. The higher initial activity of $\mathrm{NiW} / \mathrm{HB}$ than $\mathrm{NiW} / \mathrm{Al}_{2} \mathrm{O}_{3}$ might be partly attributed to its higher sulfidation/promotion degree. However, NiW/HB-M showed higher initial activity than NiW/HB, which was different to the order of their sulfidation/promotion degrees. It could be assumed that due to very fast deactivation at the beginning of the reaction observed in Fig. 8 for zeolite based catalysts, the initial activity value is difficult to measure with a good accuracy. On the other hand, the additional mesopores in zeolite support could improve the performance of zeolite based catalysts as already reported..$^{38}$

Activity after 3 hours of NiW/HB and NiW/HB-M is much lower than their corresponding initial activity and after 6 hours it becomes below that of $\mathrm{NiW} / \mathrm{Al}_{2} \mathrm{O}_{3}$. It is well known that zeolite deactivated easily in many acid-catalytic reactions due to coke formation. ${ }^{20-22,37,39}$ Such initial deactivation caused by rapid coke formation has also been reported when zeolite was used as support of Ni hydrotreating catalyst. ${ }^{40}$ It was indicated that the amount of coke in zeolite supported catalyst quickly increased during the beginning of reaction, and then tended to be stable. In this work, the initial deactivation over NiW/HB and NiW/HB$\mathrm{M}$ in HDS reaction of thiophene could be possibly attributed to coke formation due to the strong acidity from zeolite Beta.

In this work the introduction of additional mesopores/ macropores in zeolite Beta did not inhibit the deactivation tendency even if in literature data, introduction of hierarchical pores in zeolite is reported to remarkably retard the 


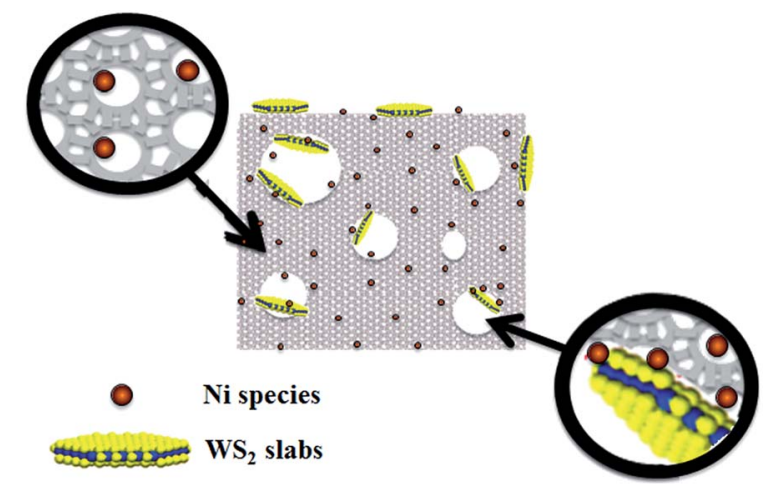

Scheme 2 Proposed imaginative diagram about location of active phase in hierarchical Beta.

deactivation caused by coke formation. ${ }^{20-22,37}$ Indeed coke formation is known to preferably occur inside the micropores that can block or cover active sites. ${ }^{41}$ In this case external active sites outside micropores are available to perform the catalytic function even when active sites inside micropores are deactivated..$^{21}$ The distribution of active sites in both micropores and mesopores/macropores in hierarchical zeolite could then explain the anti-deactivation ability. In our case, NiW/HB-M did not exhibit better anti-deactivation ability than NiW/HB that can be due to the single distribution of active species in mesopores/macropores as shown in Scheme 2.

\subsection{Improvement of the anti-deactivation ability of hierarchical Beta supported catalyst}

Considering that this deactivation might be caused by the coke formation, it was attempted to mix NiW/HB-M with $\mathrm{NiW} / \mathrm{Al}_{2} \mathrm{O}_{3}$ in different proportions to inhibit deactivation as the additional alumina could trap coke precursors on the alumina surface ${ }^{42}$ and decrease the acidity of the catalyst. The comparison of the acidity of different supports obtained by $\mathrm{NH}_{3}$-TPD is listed in Table 6. Obviously, the support $\mathrm{Al}_{2} \mathrm{O}_{3}$ support possesses the least number of acid sites and the weakest acidity.

The catalytic activities of mixed catalysts in the HDS of thiophene are presented in Fig. 10. Obviously, the addition of $\mathrm{NiW} / \mathrm{Al}_{2} \mathrm{O}_{3}$ into NiW/HB-M greatly inhibited the deactivation of the catalysts. The deactivation of NiW/HB-M was remarkably inhibited when the content of $\mathrm{NiW} / \mathrm{Al}_{2} \mathrm{O}_{3}$ was increased to $80 \mathrm{wt} \%$ (NiW/20HB-M). The steady-state activity of NiW/20HB-M $\left(276 \mathrm{~L} \mathrm{~h}^{-1} \mathrm{~mol}^{-1} \mathrm{~W}\right)$ was about 1.5 times as that of NiW/HB-M $\left(195 \mathrm{~L} \mathrm{~h}^{-1} \mathrm{~mol}^{-1} \mathrm{~W}\right)$ and $\mathrm{NiW} / \mathrm{Al}_{2} \mathrm{O}_{3}\left(177 \mathrm{~L} \mathrm{~h}^{-1} \mathrm{~mol}^{-1} \mathrm{~W}\right)$. The

Table 6 Acidity of different supports measured by $\mathrm{NH}_{3}-\mathrm{TPD}$

\begin{tabular}{llll}
\hline Samples & $\begin{array}{l}\text { Desorption } \\
\text { temperature }\left({ }^{\circ} \mathrm{C}\right)\end{array}$ & $\begin{array}{l}\text { Number of acid } \\
\text { sites }\left(\mu \mathrm{mol} \mathrm{g}{ }^{-1}\right)\end{array}$ \\
\hline $\mathrm{Al}_{2} \mathrm{O}_{3}$ & 249 & - & 204 \\
$\mathrm{HB}$ & 280 & 450 & 1170 \\
$\mathrm{HB}-\mathrm{M}$ & 260 & 440 & 920 \\
$\mathrm{NaB}$ & 290 & - & 910 \\
$\mathrm{NaB}-\mathrm{M}$ & 280 & - & 600
\end{tabular}

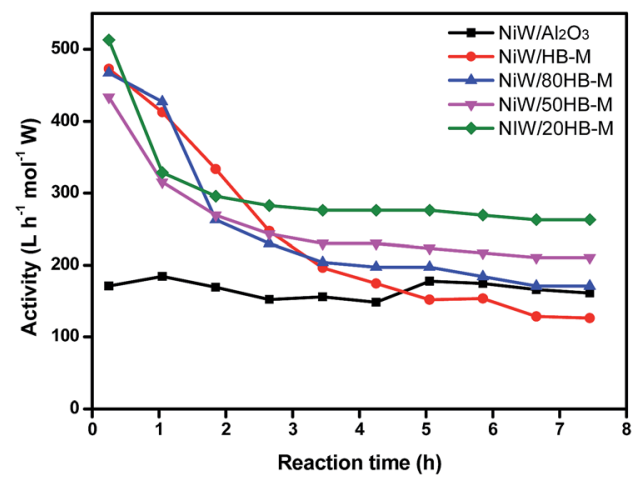

Fig. 10 Catalytic activity of mixed catalysts with time-on-stream in HDS of thiophene.

same method was also used to prepare the mixed catalysts of $\mathrm{NiW} / \mathrm{HB}$ and $\mathrm{NiW} / \mathrm{Al}_{2} \mathrm{O}_{3}$. The result indicated that deactivation can be also inhibited by this strategy. However, the steady-state activity $\left(212 \mathrm{~L} \mathrm{~h}^{-1} \mathrm{~mol}^{-1} \mathrm{~W}\right)$ of NiW/20HB with the same content of NiW/ $/ \mathrm{Al}_{2} \mathrm{O}_{3}$ was still lower than that of NiW/20HB-M.

Another strategy to inhibit the deactivation was to use $\mathrm{Na}^{+}$-exchanged Betas as support of NiW catalysts, by reducing the acidity of the support. It can be seen from the results of $\mathrm{NH}_{3}$-TPD that $\mathrm{H}$-form Beta possessed both strong and weak acid sites. After $\mathrm{Na}^{+}$ion-exchange, the desorption peak corresponding to the strong acid sites in H-form Beta disappeared (Fig. 11), suggesting the ion exchange process is efficient for decreasing the acidity of H-Beta.

Their catalytic activities were shown in Fig. 12 and show that deactivation can be restrain by using $\mathrm{Na}^{+}$exchanged zeolites. NiW/NaB-M exhibited a steady-state activity $330 \mathrm{~L} \mathrm{~h}^{-1} \mathrm{~mol}^{-1} \mathrm{~W}$ that can be compared to that of NiW/HB-M equal to $195 \mathrm{~L} \mathrm{~h}^{-1}$ $\mathrm{mol}^{-1} \mathrm{~W}$. Also, a similar effect was observed over NiW/NaB presenting an improved steady-state activity reaching $190 \mathrm{~L} \mathrm{~h}^{-1} \mathrm{~mol}^{-1} \mathrm{~W}$. These results clearly indicate that deactivation was greatly inhibited by this strategy and thus the catalytic performance of both NiW/HB and NiW/HB-M was remarkably improved. However, some authors reported that the sodium ion exchange on zeolite could negatively influence the crystallinity of zeolite, which might affect the hydrothermal stability of zeolite. The alumina-silicous skeleton and framework might be easily damaged in the process of regeneration. ${ }^{43}$

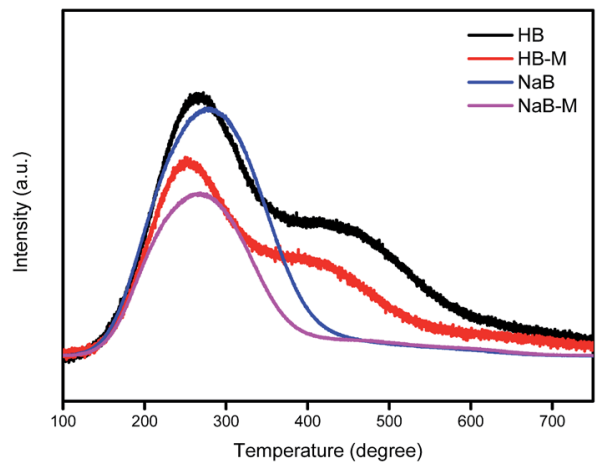

Fig. $11 \mathrm{NH}_{3}$-TPD profiles for various samples. 


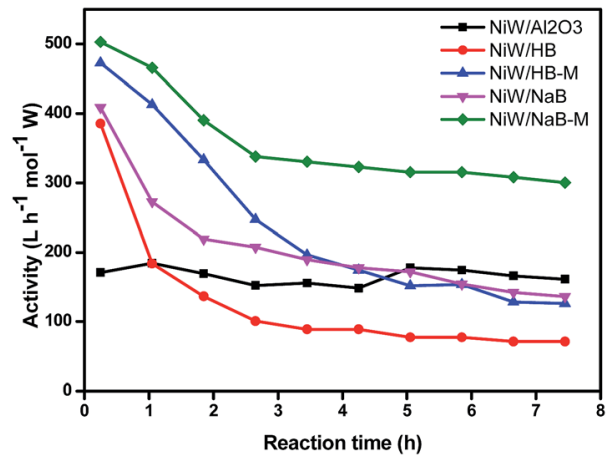

Fig. 12 Catalytic activity of various catalysts with time-on-stream in HDS of thiophene.

This enhancement could also be observed with other zeolite type such as mordenite zeolite supported TMS catalysts (ESI $\dagger$ ). The further characterizations to clarify the deactivation effect on $\mathrm{Na}^{+}$exchanged Beta supported NiW catalysts is underway.

\section{Conclusions}

NiW catalysts supported on $\gamma-\mathrm{Al}_{2} \mathrm{O}_{3}\left(\mathrm{NiW} / \mathrm{Al}_{2} \mathrm{O}_{3}\right)$, commercial Beta (NiW/HB) and hierarchical Beta (NiW/HB-M) were prepared and their catalytic performance was evaluated by HDS of thiophene. NiW/HB and NiW/HB-M exhibited higher initial catalytic activity than $\mathrm{NiW} / \mathrm{Al}_{2} \mathrm{O}_{3}$. However, important deactivation occurred over NiW/HB and NiW/HB-M showing that the introduction of additional mesopores/macropores in HB-M support could not prevent the deactivation tendency. This could be explained by the location of active phase $\left(\mathrm{WS}_{2}\right.$ and NiWS species) supposed to be located outside micropores.

Additionally, two methods have been attempted to improve the catalytic performance of NiW/HB-M in HDS of thiophene by inhibiting the deactivation of catalyst. One method is the mechanical mixing of NiW/HB-M with $\mathrm{NiW} / \mathrm{Al}_{2} \mathrm{O}_{3}$. The other one is the use of $\mathrm{Na}^{+}$-exchanged zeolite as support of $\mathrm{NiW}$ catalyst. Both methods are very efficient and lead to steady-state activities 1.5 times and twice higher respectively than that of $\mathrm{NiW} / \mathrm{Al}_{2} \mathrm{O}_{3}$, reference catalyst.

\section{Acknowledgements}

Martine Trentesaux is acknowledged for catalysts characterization by XPS. Olivier Gardoll is acknowledged for $\mathrm{NH}_{3}$-TPD experiments. Laurent d'Apolito is acknowledged for the homemade IR glass cell design and realization. The TEM facility in Lille (France) is supported by the Conseil Regional du Nord-Pas de Calais, and the European Regional Development Fund (ERDF). The authors acknowledge the financial support from the Fundamental Research Funds for the Central Universities (Grant No. HIT. NSRIF. 2015046), the Scientific Research Starting Funding from Harbin Institute of Technology, the Scientific Research Foundation for the Returned Overseas Chinese Scholars, State Education Ministry, and the Program
Caiyuanpei (project No. 30323NF) between China (CSC)-France (Campus-France).

\section{Notes and references}

1 A. Stanislaus, A. Marafi and M. S. Rana, Catal. Today, 2010, 153, 1.

2 H. Topsoe, B. S. Clausen and F. E. Massoth, in Catalysis Science and Technology, Hydrotreating Catalysis, ed., J. R. Anderson and M. Boudart, 1996, 11, pp. 310.

3 P. A. Nikulshin, V. A. Salnikov, A. V. Mozhaev, P. P. Minaev, V. M. Kogan and A. A. Pimerzin, J. Catal., 2014, 309, 386.

4 J. Marques, D. Guillaume, I. Merdrignac, D. Espinat and S. Brunet, Appl. Catal., B, 2011, 101, 727.

5 B. Pawelec, J. L. G. Fierro, A. Montesinos and T. A. Zepeda, Appl. Catal., B, 2008, 80, 1.

6 V. La Parola, M. L. Testa and A. M. Venezia, Appl. Catal., B, 2012, 119-120, 248.

7 S. A. Giraldo and A. Centeno, Catal. Today, 2008, 133-135, 255.

8 A. M. Venezia, R. Murania, V. La Parola, B. Pawelec and J. L. G. Fierro, Appl. Catal., A, 2010, 383, 211.

9 W. Chen, F. Mauge, J. van Gestel, H. Nie, D. Li and X. Long, J. Catal., 2013, 304, 47.

10 Y. Wang, B. Wang, A. Rives and Y. Sun, Energy Environ. Focus, 2014, 3, 1.

11 D. Zhang, A. Duan, Z. Zhao, X. Wang, G. Jiang, J. Liu, C. Wang and M. Jin, Catal. Today, 2011, 175, 477.

12 D. Solis, A. L. Agudo, J. Ramirez and T. Klimova, Catal. Today, 2006, 116, 469.

13 Q. Huo, T. Dou, Z. Zhao and H. Pan, Appl. Catal., A, 2010, 381, 101.

14 Y. Fan, H. Xiao, G. Shi, H. Liu, Y. Qian, T. Wang, G. Gong and X. Bao, J. Catal., 2011, 279, 27.

15 F. Bataille, J. L. Lemberton, G. Perot, P. Leyrit, T. Cseri, N. Marchal and S. Kasztelan, Appl. Catal., A, 2001, 220, 191.

16 D. Solis, T. Klimova, R. Cuevas, J. Ramirez and A. LopezAgudo, Catal. Today, 2004, 98, 201.

17 Q. Huo, Y. Gong, T. Dou, Z. Zhao, H. Pan and F. Deng, Energy Fuels, 2010, 24, 3764.

18 K. T. Hojholt, P. N. R. Vennestrom, R. Tiruvalam and P. Beato, Chem. Commun., 2011, 47, 12864.

19 T. Tang, L. Zhang, W. Fu, Y. Ma, J. Xu, J. Jiang, G. Fang and F.-S. Xiao, J. Am. Chem. Soc., 2013, 135, 11437.

20 R. Srivastava, M. Choi and R. Ryoo, Chem. Commun., 2006, 43, 4489.

21 J.-C. Kim, K. Cho and R. Ryoo, Appl. Catal., A, 2014, 470, 420. 22 Y. Liu, N. Zhao, H. Xian, Q. Cheng, Y. Tan, N. Tsubaki and X. Li, ACS Appl. Mater. Interfaces, 2015, 7, 8398.

23 Y. Wang, Y. Sun, C. Lancelot, C. Lamonier, J. Morin, B. Revel, L. Delevoye and A. Rives, Microporous Mesoporous Mater., 2015, 206, 42.

24 K. Ben Tayeb, C. Lamonier, C. Lancelot, M. Fournier, E. Payen, A. Bonduelle and F. Bertoncini, Catal. Today, 2010, 150, 207. 
25 K. Ben Tayeb, C. Lamonier, M. Fournier, E. Payen, F. Bertoncini and A. Bonduelle, Am. Chem. Soc., Div. Fuel Chem., Prepr. Symp., 2008, 53, 9.

26 C. Martin, C. Lamonier, M. Fournier, O. Mentre, V. Harle, D. Guillaume and E. Payen, Chem. Mater., 2005, 17, 4438.

27 K. Ben Tayeb, C. Lamonier, C. Lancelot, M. Fournier, A. Bonduelle and F. Bertoncini, Appl. Catal., B, 2012, 126, 55. 28 L. Ding, Y. Zheng, Z. Zhang, Z. Ring and J. Chen, J. Catal., 2006, 241, 435.

29 L. Ding, Y. Zheng, Z. Zhang, Z. Ring and J. Chen, Appl. Catal., A, 2007, 319, 25-37.

30 R. Tian, B. Shen, F. Wang, C. Lu and C. Xu, Energy Fuels, 2009, 23, 55.

31 J. N. Diaz de Leon, M. Picquart, L. Massin, M. Vrinat and J. A. de los Reyes, J. Mol. Catal. A: Chem., 2012, 363-364, 311.

32 H. R. Reinhoudt, E. Crezee, A. D. van Langeveld, P. J. Kooyman, J. A. R. van Veen and J. A. Mouljin, J. Catal., 2000, 196, 315.

33 G. Wan, A. Duan, Y. Zhang, Z. Zhao, G. Jiang, D. Zhang, Z. Gao, J. Liu and K. H. Chung, Energy Fuels, 2009, 23, 3846.
34 L. Ding, Y. Zheng, H. Yang and R. Parviz, Appl. Catal., A, 2009, 353, 17.

35 Y. V. Joshi, P. Ghosh, M. Daage and W. N. Delgass, J. Catal., 2008, 257, 71.

36 B. S. Zhang, Y. J. Yi, W. Zhang, C. H. Liang and D. S. Su, Mater. Charact., 2011, 62, 684.

37 H. Yang, Z. Liu, H. Gao and Z. Xie, Appl. Catal., A, 2010, 379, 166.

38 Y. Wang, J. Wu and S. Wang, RSC Adv., 2013, 3, 12635.

39 M. Guidotti, C. Canaff, J.-M. Coustard, P. Magnoux and M. Guisnet, J. Catal., 2005, 230, 375.

40 J. Aguado, D. P. Serrano, J. M. Escola and L. Briones, Fuel, 2013, 109, 679.

41 M. L. Occelli, J. P. Olivier and A. Auroux, J. Catal., 2002, 209, 385.

42 J. S. J. Hargreaves and A. L. Munnoch, Catal. Sci. Technol., 2013, 3, 1165.

43 L.-E. Sandoval-Diaz, L.-A. Palomeque-Forero and C. A. Trujillo, Appl. Catal., A, 2011, 393, 171. 